\title{
Fat embolism after fractures in Duchenne muscular dystrophy: an underdiagnosed complication? A systematic review
}

This article was published in the following Dove Press journal:

Therapeutics and Clinical Risk Management

10 October 2017

Number of times this article has been viewed

\author{
David Feder' \\ Miriam Eva Koch' \\ Beniamino Palmieri² \\ Fernando Luiz Affonso \\ Fonseca' \\ Alzira Alves de Siqueira \\ Carvalho ${ }^{3}$ \\ 'Pharmacology Department, Faculdade \\ de Medicina do ABC, Santo André, \\ São Paulo, Brazil; ${ }^{2}$ Department \\ of General Surgery and Surgical \\ Specialties, University of Modena \\ and Reggio Emilia Medical School, \\ Surgical Clinic, Modena, Italy; \\ ${ }^{3}$ Neuroscience Department, Faculdade \\ de Medicina do ABC, Santo André, \\ São Paulo, Brazil
}

\begin{abstract}
Duchenne muscular dystrophy is the most frequent lethal genetic disease. Several clinical trials have established both the beneficial effect of steroids in Duchenne muscular dystrophy and the well-known risk of side effects associated with their daily use. For many years it has been known that steroids associated with ambulation loss lead to obesity and also damage the bone structure resulting in the bone density reduction and increased incidence of bone fractures and fat embolism syndrome, an underdiagnosed complication after fractures. Fat embolism syndrome is characterized by consciousness disturbance, respiratory failure and skin rashes. The use of steroids in Duchenne muscular dystrophy may result in vertebral fractures, even without previous trauma. Approximately $25 \%$ of patients with Duchenne muscular dystrophy have a long bone fracture, and $1 \%$ to $22 \%$ of fractures have a chance to develop fat embolism syndrome. As the patients with Duchenne muscular dystrophy have progressive cardiac and respiratory muscle dysfunction, the fat embolism may be unnoticed clinically and may result in increased risk of death and major complications. Different treatments and prevention measures of fat embolism have been proposed; however, so far, there is no efficient therapy. The prevention, early diagnosis and adequate symptomatic treatment are of paramount importance. The fat embolism syndrome should always be considered in patients with Duchenne muscular dystrophy presenting with fractures, or an unexplained and sudden worsening of respiratory and cardiac symptoms.
\end{abstract}

Keywords: Duchenne muscular dystrophy, fat embolism syndrome, fractures

\section{Introduction}

Duchenne muscular dystrophy (DMD) is the most frequent infantile hereditary myopathy, an X-linked disorder, caused by a mutation in the dystrophin gene. The product of this gene, dystrophin, is a protein localized in the subsarcolemmal area of muscle fiber and is responsible for membrane stability preventing cell damage induced by contraction. ${ }^{1,2}$

Several clinical trials have established both the beneficial effect of steroids in DMD and the well-known risk of side effects associated with their daily use. Steroids are recommended in the international standards of care guidelines for DMD because of their ability to slow the progression of weakness, reduce the development of scoliosis (curvature of the spine) and delay breathing and heart problems. ${ }^{1,2}$

For many years, it has been known that steroids associated with ambulation loss lead to obesity and also damage the bone structure resulting in the bone density reduction and increased incidence of bone fractures which vary between $25 \%$ cases in long bones to $19 \%$ in vertebras..$^{1,2}$
Pharmacology Department, Faculdade de Medicina do ABC, Av. Lauro Gomes, 2000 Santo Andre, São Paulo 09060-870, Brazil

Email feder2005@gmail.com 
Therefore, the factors described earlier are the cause of DMD patient's predisposition to develop fat embolism syndrome (FES), an underdiagnosed complication after fractures, characterized by consciousness disturbance, respiratory failure and skin rashes. As the patients with DMD have progressive cardiac and respiratory muscle dysfunction, the FES may be unnoticed clinically and may result in increased risk of death and major complications. In addition, the minor cases are hardly diagnosed..$^{3-5}$

The presence of fat droplets in the microcirculation has been found in about $95 \%$ of bone fractures and may cause a fat embolism. The FES is present in about $19 \%$ of cases of trauma being characterized by skin rash, respiratory failure and consciousness disturbance. ${ }^{3}$ However, the condition is usually asymptomatic as the embolus is destroyed before causing any injury.

The diagnosis of FES is clinical. According to Gurd and Wilson' $s^{5}$ criteria, the cardinal symptoms constitute the syndrome triad: skin rash and respiratory and neurologic alterations. The minor symptoms include tachycardia, disturbance of retina, fever and diuresis reduction. ${ }^{4}$ It also could provoke thrombocytopenia over $50 \%$, hemoglobin decrease over $20 \%$ and fatty macroglobulinemia.

The clinical manifestations do not help in the early diagnosis as the symptoms may develop 24-72 $\mathrm{h}$ after trauma (and especially after fractures) when lipid microparticles become impacted in the pulmonary microvasculature and other microvascular beds such as in the brain. The onset of symptoms may coincide with the agglutination and degradation of fat emboli. ${ }^{4,5}$

Some hypotheses have been proposed as possible mechanisms of FES are important to highlight them. 1) The mechanic theory shows that trauma increases the intramedullary pressure, releasing lipid particles from the sinusoids, obstructing the microcirculation. ${ }^{3}$ 2) The lipase theory suggests that the increased plasmatic level of lipase after lesion promotes saponification and causes mobilization of fat particles. 3) According to the free fatty acid theory, trauma stimulates the inflammatory process, releasing free fatty acids, which cause vasculitis. 4) In relation to the shock and coagulation hypothesis, trauma would lead to hypovolemia, reducing the blood flow velocity and activating the coagulation. ${ }^{4}$

Different treatments and prevention measures of FES have been proposed; however, so far, there is no efficient therapy. ${ }^{6}$

\section{Materials and methods}

This is a systematic review of the literature. The database search was finished in May 28, 2016. The content was

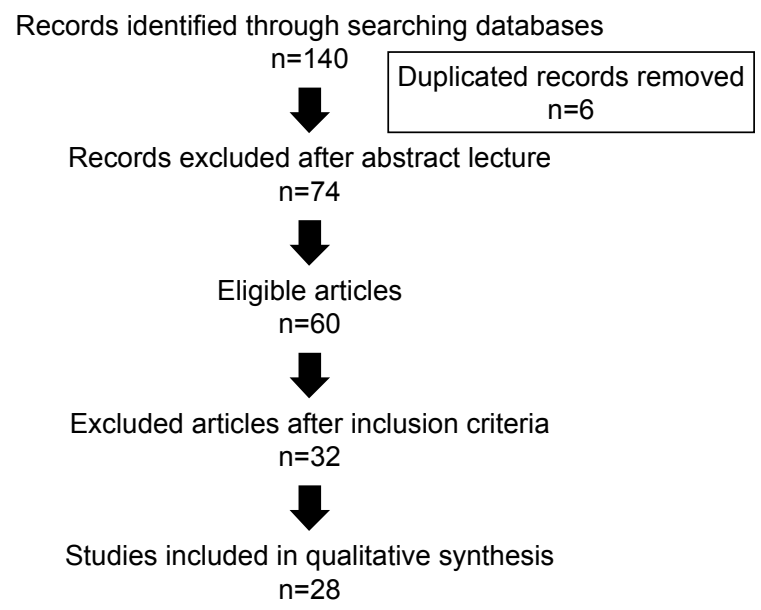

Figure I Literature flowchart.

researched in the databases: PubMed, Lilacs, Science Direct, Wiley Online Library and HighWire. The keywords used in the advanced search were the following: "Duchenne dystrophy and fat embolism," "Duchenne dystrophy and fracture" and "fracture and fat embolism epidemiology" (Figure 1; Table 1).

\section{Results}

After extensive review of the literature about FES and DMD, we found just five articles reporting patients with this association. A total of 16 cases were described, and they are summarized in Table 2.

In 1992, the first case of DMD related to FES was published by Pender et al, ${ }^{7}$ describing a 12-year-old boy who suffered a fracture followed by consciousness disturbance, respiratory failure and skin rash with a recovery.

Amador et $\mathrm{al}^{8}$ reported a case of a 14-year-old boy, who suffered a fracture after falling from the wheelchair $48 \mathrm{~h}$ before hospitalization. While the trauma was being treated, there was a neurological decay. The treatment was performed successfully.

McAdam et $\mathrm{al}^{9}$ presented the first article about fat embolism as a result of minor trauma without fracture in five boys

Table I Databases and different keywords

\begin{tabular}{llllll}
\hline Keywords & PubMed & $\begin{array}{c}\text { Lilacs } \\
\text { Science } \\
\text { Direct }\end{array}$ & $\begin{array}{l}\text { Wiley } \\
\text { Online }\end{array}$ & HighWire \\
\hline $\begin{array}{l}\text { Duchenne muscular } \\
\text { dystrophy } \times\end{array}$ & 4 & 3 & I & I & 4 \\
$\begin{array}{l}\text { fat embolism } \\
\begin{array}{l}\text { Duchenne } \\
\text { dystrophy }\end{array}\end{array}$ & 2 & 31 & 31 & 12 & 21 \\
$\begin{array}{l}\text { fracture } \\
\begin{array}{l}\text { fracture } \times \\
\text { fat embolism }\end{array}\end{array}$ & 1 & 9 & 20 & 0 & 0 \\
\hline
\end{tabular}


Table 2 Clinical data from five different reports: FES $\times$ DMD

\begin{tabular}{|c|c|c|c|c|c|c|c|}
\hline Study & $\mathbf{N}$ & $\begin{array}{l}\text { Age } \\
\text { (years) }\end{array}$ & $\begin{array}{l}\text { Use of } \\
\text { steroids }\end{array}$ & Non-ambulant & $\begin{array}{l}\text { FES, major } \\
\text { criteria } \geq 2\end{array}$ & $\begin{array}{l}\text { FES, minor } \\
\text { criteria } \geq I\end{array}$ & $\begin{array}{l}\text { Evolution } \\
\text { death }\end{array}$ \\
\hline Pender et $\mathrm{al}^{7}$ & I & 12 & No & Y & Y, I & Y, I & 0 \\
\hline Amador et $\mathrm{a}^{8}$ & I & 14 & Y, I & Y, I & Y, I & $\mathrm{Y}, \mathrm{I}$ & 0 \\
\hline Medeiros et al ${ }^{10}$ & 8 & $14-13$ & Y, 7 & Y, 7 & $\mathrm{Y}, 8$ & Y, 8 & 3 \\
\hline McAdam et al $\left.\right|^{1,9}$ & 5 & $14-23$ & $\mathrm{Y}, 4$ & $\mathrm{Y}, 5$ & $\mathrm{Y}, 5$ & $\mathrm{Y}, 5$ & 4 \\
\hline Stein et $\mathrm{al}^{11}$ & 1 & 15 & Y, I & Y, I & Y, I & Y, I & 0 \\
\hline
\end{tabular}

Note: Y, present; No, absent.

Abbreviations: DMD, Duchenne muscular dystrophy; FES, fat embolism syndrome.

with DMD. Four patients were taking corticosteroids daily and had a fatal outcome. All patients fulfilled the clinical criteria for FES.

Medeiros et a $\mathrm{a}^{10}$ reported eight cases of fat embolism in patients with DMD who had sustained low-energy trauma.

Recently, Stein et a ${ }^{11}$ described a case report about a patient with DMD exhibiting cardiopulmonary, neurologic and visual signs consistent with FES after minor trauma.

\section{Discussion}

In this review, we discuss the causes of FES and fractures in patients with DMD as well as the correlation among them and the difficulty of an accurate diagnosis.

Even though FES has been known for decades, many factors remain undiscovered in the scientific community: could be the multifactorial pathophysiology of FES?

\section{What about the effective therapeutic approaches and the real epidemiology of its clinical manifestations?}

When examining the literature of FES, the occurrence can vary greatly among the studies reaching values of $22 \%$, although there is a great difficultly in diagnosing minor cases. ${ }^{12}$

Although there is a difficulty to obtain an early diagnosis, a prompt treatment would be vital to have a better prognosis. Differential diagnosis includes aspiration pneumonia/ pneumonitis, pulmonary embolism, traumatic brain injury, stroke and seizures, which could result in unhelpful diagnostics and procedures. In relation to thrombosis, conditions such as cerebral infarction and pulmonary embolism are serious life-threatening complications of DMD, as activated in the coagulation system as well. ${ }^{13-18}$

Thus, it is important to keep in mind the possibility of FES during postoperative situations or after fractures as patients with DMD also have cardiac and respiratory muscle dysfunctions from the disease itself, which could mask the right diagnosis of FES.

We found only a few reports about fractures followed by FES in patients with DMD.
The occurrence of FES has also been described in 5-14-year-old children experiencing long bone and pelvic fractures. It is estimated that FES incidence in children is 100 times lower than in adults, and this could be due to the lower fat marrow content and small amounts of liquid triolein (glyceryl trioleate) in children's bone marrow. ${ }^{19}$ On the other hand, osteoporosis, obesity, immobility and steroid therapy contribute to the increased fat on the bone marrow. ${ }^{9}$

Although the fat embolism is common after long bone fractures, the FES is not a well-recognized complication in patients with DMD.

The few remote cases reported could be explained by the heterogeneous presentation and problems with diagnostic testing. Except for the skin rush, there are no pathognomonic signs. In addition, an asymptomatic latent period of about 12-48 h usually precedes the symptoms. ${ }^{7}$

The cases reported in the literature showed that the age onset of FES in DMD started between 12 and 23 years old. Almost all patients were non-ambulant and were corticosteroid users suggesting that immobility and steroid use could trigger the FES (Table 2).

The review articles stress the fragile bone formation and muscle atrophy in patients with DMD which could predispose to the occurrence of falls, resulting in ambulant loss. The consequent immobilization would predispose to obesity overloading the bone structure. Conversely, steroids increase the incidence of obesity and decrease bone density causing vertebral fractures and facilitating clinical evolution to fat embolism.

Different treatments and prevention of FES have been published; however, there is no efficient treatment until now. ${ }^{6}$ The standard procedure consists of supporting measures beyond the early fixation of the broken bone ${ }^{8}$ but above all, early diagnoses should for instance be considered as part of the initial treatment. One of the most important measures in FES consists of ensuring good arterial oxygenation. High flow rate oxygen is given to maintain the arterial oxygen tension in the normal range. ${ }^{20}$ But in DMD, the increased supply of oxygen can aggravate hypoventilation and therefore lead to death. ${ }^{21}$ In patients with DMD, the oxygen 
supply must be made with assisted ventilation (invasive or not). ${ }^{21}$ In addition, maintenance of intravascular volume is important, because shock can exacerbate the lung injury caused by FES. ${ }^{20}$ In DMD, due to the possibility of cardiac dysfunction, the supply of fluids should be taken carefully and use of vasoactive drugs should be important.

Aiming to improve life quality, this review highly advocates the adoption of the DMD Care Considerations Working Group for the medical staff in charge of DMD cases. ${ }^{21}$ According to the guideline, the patients' nutrition and fracture history needs to be detailed. In addition, the following examinations should be performed to prevent complications: calcium, phosphorus, alkaline phosphatase, $25 \mathrm{OH}$ vitamin D level, magnesium and parathyroid hormone levels, urine calcium, sodium and creatinine, and annually, bone densitometry for patients at risk (history of fractures, glucocorticoid use or Z-score $<-2$ ). Back X-rays should be taken in patients with back pain or with kyphoscoliosis to rule out vertebral compression fractures. Possible interventions suggested are as follows: Vitamin D supplementation in case of deficiency, calcium, intravenous bisphosphonates for vertebral compression fractures and a diet rich in vitamin D and calcium. For patients taking steroids, it is also important to encourage weight-bearing activities, multivitamin supplements with vitamin D3 and to consider bisphosphonates use. ${ }^{22}$ It would be safer that patients carry an emergency card warning of the risk of FES after fractures.

Ness and Apkon ${ }^{22}$ advocate the identification of fractures on admission and an implementation of a mitigation plan that focuses on ensuring no child acquires a fracture while hospitalized, especially in high-risk patients such as neuromuscular ones.

In additional, the study by James et $\mathrm{a}^{23}$ revealed that the main risk factor for fractures in patients with DMD/Becker muscular dystrophy consisted of full-time wheelchair use. Consequently, it is suggested to pay special attention to assure the use of seatbelts, instruct the families how to perform safe transfers and explain the risks. As for fractures in ambulatory boys, the use of internal fixation and weight-bearing measures are recommended. In addition, before any surgery, it is vital to discuss the case with the child's neuromuscular team members, including cardiologist and pulmonologist.

These measures can improve life quality and prevent events such as fractures and FES.

\section{Conclusion}

A high index of suspicion is needed to make the diagnosis of the fatal FES.
As the patients with DMD have progressive cardiac and respiratory muscle dysfunction, the FES may be unnoticed clinically and may result in increased risk of death and major complications. So, we do recommend to always keep in mind the diagnoses of FES.

Early detection and treatment is the key to a successful outcome and also to reduce the progression and severity of clinical picture.

\section{Disclosure}

The authors report no conflicts of interest in this work.

\section{References}

1. McAdam LC, Mayo AL, Alman BA, Biggar WD. The Canadian experience with long term deflazacort treatment in Duchenne muscular dystrophy. Acta Myol. 2012;31(1):16-20.

2. Morgenroth VH, Hache LP, Clemens PR. Insights into bone health in Duchenne muscular dystrophy. Bonekey Rep. 2012;1:9.

3. Kwiatt ME, Seamon MJ. Fat embolism syndrome. Int J Crit Illn Inj Sci. 2013;3(1):64-68.

4. Mellor A, Soni N. Fat embolism. Anaesthesia. 2001;56(2):145-154.

5. Gurd AR, Wilson RI. The fat embolism syndrome. J Bone Joint Surg Br. 1974;56B:408-416.

6. Bulger EM, Smith DG, Maier RV, Jurkovich GJ. Fat embolism syndrome. A 10-year review. Arch Surg. 1997;132(4):435-439.

7. Pender ES, Pollack CV Jr, Evans OB. Fat embolism syndrome in a child with muscular dystrophy. J Emerg Med. 1992;10:705-711.

8. Amador EV, Villamarín FG, Quintero MP. Embolismo graso en un niño con distrofia muscular de Duchenne y fractura bilateral de fémur. Una rara asociación. Rev Fac Med. 2007;55(1):58-62.

9. McAdam LC, Rastogi A, Macleod K, Douglas Biggar W. Fat embolism syndrome following minor trauma in Duchenne muscular dystrophy. Neuromuscul Disord. 2012;22(12):1035-1039.

10. Medeiros MO, Behrend C, King W, Sanders J, Kissel J, Ciafaloni E. Fat embolism syndrome in patients with Duchenne muscular dystrophy. Neurology. 2013;80(14):1350-1352.

11. Stein L, Herold R, Austin A, Beer W. Fat embolism syndrome in a child with Duchenne muscular dystrophy after minor trauma. J Emerg Med. 2016;50(5):e223-e226.

12. Talbot M, Schemitsch EH. Fat embolism syndrome: history, definition, epidemiology. Injury. 2006;37(4 suppl):S3-S7.

13. Matsuishi T, Yano E, Terasawa K, et al. Basilar artery occlusion in a case of Duchenne muscular dystrophy. Brain Dev. 1982;4(5):379-384.

14. Biller J, Ionasescu V, Zellweger H, Adams HP, Schultz DT. Frequency of cerebral infarction in patients with inherited neuromuscular diseases. Stroke. 1987;18(4):805-807.

15. Gaffney JF, Kingston WJ, Metlay LA, Gramiak R. Left ventricular thrombus and systemic emboli complicating the cardiomyopathy of Duchenne's muscular dystrophy. Arch Neurol. 1989;46(11):1249-1252.

16. Riggs T. Cardiomyopathy and pulmonary emboli in terminal Duchenne's muscular dystrophy. Am Heart J. 1990;119(3):690-693.

17. Hanajima R, Kawai M. Incidence of cerebral infarction in Duchenne muscular dystrophy. Muscle Nerve. 1996;19(7):928.

18. Saito T, Yamamoto Y, Matsumura T, Nozaki S, Fujimura H, Shinno S. Coagulation system activated in Duchenne muscular dystrophy patients with cardiac dysfunction. Brain Dev. 2005;27(6):415-418.

19. Gossling HR, Pellegrini VD Jr. Fat embolism syndrome: a review of the pathophysiology and physiological basis of treatment. Clin Orthop. 1982;165:68-82.

20. Shaikh N. Emergency management of fat embolism syndrome. J Emerg Trauma Shock. 2009;2(1):29-33. 
21. Bushby K, Finkel R, Birnkrant DJ, et al; DMD Care Considerations Working Group. Diagnosis and management of Duchenne muscular dystrophy, part 2: implementation of multidisciplinary care. Lancet Neurol. 2010;9(2):177-189.

22. Ness K, Apkon SD. Bone health in children with neuromuscular disorders: an Interdisciplinary Approach. J Pediatr Rehabil Med. 2014;7: $133-142$.
23. James KA, Cunniff C, Apkon SD, et al. Risk factors for first fractures among males with Duchenne or Becker Muscular Dystrophy. J Pediatr Orthop. 2015;35(6):640-644.

\section{Publish your work in this journal}

Therapeutics and Clinical Risk Management is an international, peerreviewed journal of clinical therapeutics and risk management, focusing on concise rapid reporting of clinical studies in all therapeutic areas outcomes, safety, and programs for the effective, safe, and sustained use of medicines. This journal is indexed on PubMed Central, CAS
EMBase, Scopus and the Elsevier Bibliographic databases. The manuscript management system is completely online and includes a very quick and fair peer-review system, which is all easy to use. Visit http://www.dovepress.com/testimonials.php to read real quotes from published authors.

Submit your manuscript here: http://www.dovepress.com/therapeutics-and-clinical-risk-management-journal 